\title{
BMJ Open Knowledge of and attitudes toward clinical trials in Saudi Arabia: a cross- sectional study
}

\author{
Nedal Al-Rawashdeh, ${ }^{1,2,3,4}$ Rana Damsees, ${ }^{1,2,3,4}$ Majed Al-Jeraisy, ${ }^{1,3,4}$ \\ Eman Al Qasim, ${ }^{1,3,4}$ Ahmad M Deeb (1) 1,3,4
}

To cite: Al-Rawashdeh N, Damsees R, Al-Jeraisy M, et al. Knowledge of and attitudes toward clinical trials in Saudi Arabia: a crosssectional study. BMJ Open 2019;9:e031305. doi:10.1136/ bmjopen-2019-031305

- Prepublication history for this paper is available online. To view these files, please visit the journal online (http://dx.doi. org/10.1136/bmjopen-2019031305).

Received 27 April 2019 Revised 10 September 2019 Accepted 26 September 2019

Check for updates

(c) Author(s) (or their employer(s)) 2019. Re-use permitted under CC BY-NC. No commercial re-use. See rights and permissions. Published by BMJ.

${ }^{1}$ Research Office, King Abdullah International Medical Research Center, Riyadh, Saudi Arabia

${ }^{2}$ The Office of Scientific Affairs and Research, King Hussein

Cancer Center, Amman, Jordan ${ }^{3}$ King Saud bin Abdulaziz

University for Health Sciences, Riyadh, Saudi Arabia

${ }^{4}$ Ministry of the National Guard - Health Affairs, Riyadh, Saudi Arabia

Correspondence to

Ahmad M Deeb;

rn_a_deeb@hotmail.com

\section{ABSTRACT}

Objectives Clinical trials (CTs) are considered an important method for developing new treatments and providing access to potentially effective drugs that are still under investigation. Measuring the public's knowledge of and attitudes toward CTs is important for assessing their readiness for and acceptance of human drug testing, which has previously not been assessed in the Kingdom of Saudi Arabia (KSA). The objective of this study is to explore the Saudi public's knowledge of and attitudes toward CTs as well as participation in trials to test new or approved drugs.

Design Cross-sectional.

Setting The $2016 \mathrm{Al}$ Jenadriyah cultural/heritage festival in Riyadh, KSA.

Participants Participating booths and exhibition halls, as well as festival visitors, were approached to participate in the study.

Primary and secondary outcome measures Knowledge of and attitudes toward CTs.

Results The final number of participants was 938 . The responses were converted to a percentage mean score (out of 100) for each knowledge-related response and attitude. The total mean knowledge score was $56.8 \pm 24.8$ and the attitude-related score was $61.5 \pm 28.0$. Although most of the participants supported testing approved or off-label and new drugs on adult and paediatric patients, only a third $(30.5 \%)$ agreed that new drugs could be tested on healthy volunteers. The results indicated that gender, educational level, income, medical background, age and health insurance were independently associated with the level of knowledge of CTs. In terms of attitudes toward $\mathrm{CTs}$, the factors that were independently associated were gender, educational level and medical background.

Conclusions The Saudi public has a low level of knowledge and a moderately positive attitude toward CTs. There is a moderate positive correlation between the two factors such that as knowledge of CTs increases, the Saudi public will hold more positive attitudes toward CTs.

\section{INTRODUCTION}

A clinical trial (CT) is a superior research tool for advancing medical knowledge and practice as the results are considered to provide the highest level of evidence for medical practice and decision-making. ${ }^{1}$ Volunteer participation is at the core of a successful CT.

\section{Strengths and limitations of this study}

The Saudi public's knowledge of and attitudes toward clinical trials (CTs) are under-researched.

- This is the first study to explore the Saudi public's knowledge and attitudes in terms of the different phases of CTs in adult and paediatric populations.

- The main limitation is possible selection bias due to convenience sampling.

The involvement of an adequate number of participants is crucial in achieving the study's objectives, namely testing the hypothesis and answering the research questions. Failure to recruit an adequate number of participants could result in wasted time, money and effort. ${ }^{2}$ It may also delay the acceptance of the trial results and the completion of the drug development process.

Knowledge of and attitudes toward CTs are considered major challenges in participant recruitment. ${ }^{3-6}$ Several studies have reported that knowledge of CTs and attitudes toward participation are interrelated, ${ }^{7-11}$ as increased knowledge promotes a positive attitude toward CT participation. Low recruitment rates for CTs may be improved by increasing the public's knowledge about CTs ${ }^{611}$ and by highlighting how participation can contribute to the improvement of the public's health. ${ }^{12}{ }^{13}$ Improving the public's knowledge of CTs represents an important initial step in improving CT recruitment in the future. ${ }^{912} 14$

Clinical research in the Kingdom of Saudi Arabia (KSA) has made advancements during the last few decades. ${ }^{15}$ Saudi researchers have contributed to medical literature by conducting different types of research, including investigator-initiated CTs and international multicenter-sponsored CTs. ${ }^{15}$ Measuring the Saudi public's knowledge of and attitudes toward CTs is crucial for assessing their acceptance of CTs and to provide an evidence base to improve CT 
recruitment and decision-making. In addition, such an endeavour can provide reliable information that can aid researchers and healthcare leaders in strategic planning of public engagement in CT awareness campaigns. From the public's perspective, these efforts may be beneficial through increasing their knowledge and awareness of CTs, improving medical knowledge through dissemination of CT results and sharing of public preferences for future CTs.

Several studies have reported the knowledge and attitudes of patients or families toward CTs in healthcare settings in the $\mathrm{KSA}^{16-20}$; however, studies measuring the knowledge and attitudes of the general Saudi public are lacking. The purpose of this study was to assess the Saudi public's general knowledge of and attitudes toward CTs and more specifically, their attitudes toward participation in CTs for drug development.

The study addressed the following four questions: What does the Saudi public know about CTs? What is the attitude of individuals in the KSA toward CTs and participation in CTs? Is there a correlation between the level of public knowledge and the attitudes of Saudi individuals toward CTs? What factors are associated with the levels of public knowledge and attitudes toward CTs in the Saudi population?

\section{MATERIALS AND METHODS \\ Setting}

This cross-sectional study was conducted between 2 February 2016 and 19 February 2016 at the Al Jenadriyah cultural and heritage festival. The festival takes place in Riyadh and hosts millions of residents and visitors from different regions in the country. We selected this event as it provided us with a unique chance to interview a representative cross-section from all regions of the KSA.

\section{Study participants}

The study included adults of both genders who were willing to participate. A convenience sampling approach was used. Participating booths and exhibition halls in the festival were approached and festival visitors were invited to participate in the study. All participants provided informed consent by checking the YES box indicating their willingness to complete the questionnaire. Respondents did not receive any compensation for participation in the study.

\section{Patient and public involvement}

The public was not included in the development of the research questions or the design of the study. However, the questionnaire was pretested with a different sample of the general public before implementation.

\section{Sample size}

The population of the KSA is approximately 31742308 (Central Department of Statistics and Information), including 11677338 expatriates (non-Saudi). ${ }^{21}$ On the basis of this population estimate, a 0.05 margin of error, a $95 \%$ confidence level and a response rate of $50 \%$, the minimum sample size calculated for this study was 385 . We targeted a sample size of 1000 to account for sampling errors and variability between the characteristics of our sample and the general Saudi population.

\section{Data collection}

A structured questionnaire, developed in Arabic, was divided into three sections: demographic information, knowledge and attitudes.

The following variables were included in the demographic information section: gender, age, educational level, monthly income, nationality, residential area, marital status, employment status, health insurance, chronic diseases, medical background (working in a healthcare facility or having health-related education) and previous participation in medical research.

The knowledge section was composed of 12 questions, and the participants' responses were scored as correct (score $=1)$ or incorrect/not sure $($ score $=0)$. The total knowledge score was converted to a percentage mean score with a possible maximum value of 100 , where a score of 100 indicates perfect knowledge of CTs.

The attitude section was composed of 9 direct questions, and participant answers were scored as positive (score $=1$ ) or negative/not sure $($ score $=0)$. The total attitude score was converted to a percentage mean score with a possible maximum value of 100 , where a score of 100 indicates a positive attitude toward CTs.

Based on previous studies, the overall knowledge and attitude levels were classified into three categories following Bloom's cut-off point criteria: above $80 \%$ (high level), $60 \%$ to $79 \%$ (moderate level) and less than $60 \%$ (low level). ${ }^{22-24}$

We used simple language so as to enable the participants to answer the questions even if they were not aware of CTs. The questionnaire was validated using a content validation process. A panel of expert analysts evaluated the questions, rating each one as essential, useful or irrelevant in the context of measuring knowledge and attitudes. The questionnaire was pretested using a sample of 28 participants. As a result of the pretest, complex scientific terms were simplified. Reliability was tested by calculating the Cronbach's alpha for the pretest sample for both the knowledge and attitude sections (21 items). The Cronbach's alpha was 0.81 .

\section{Data analysis}

The categorical variables were represented as frequency and percentage and the continuous variables as mean \pm SD. Normality was tested by the skewness coefficient, which indicated that the knowledge and attitude data were normally distributed. The Student's t-test and one-way analysis of variance were used as tests of significance. The Pearson's correlation coefficient was used to calculate the correlation between the knowledge and attitude scores. A generalised linear model was used to 
Table 1 Participant characteristics and unadjusted factors associated with knowledge and attitudes

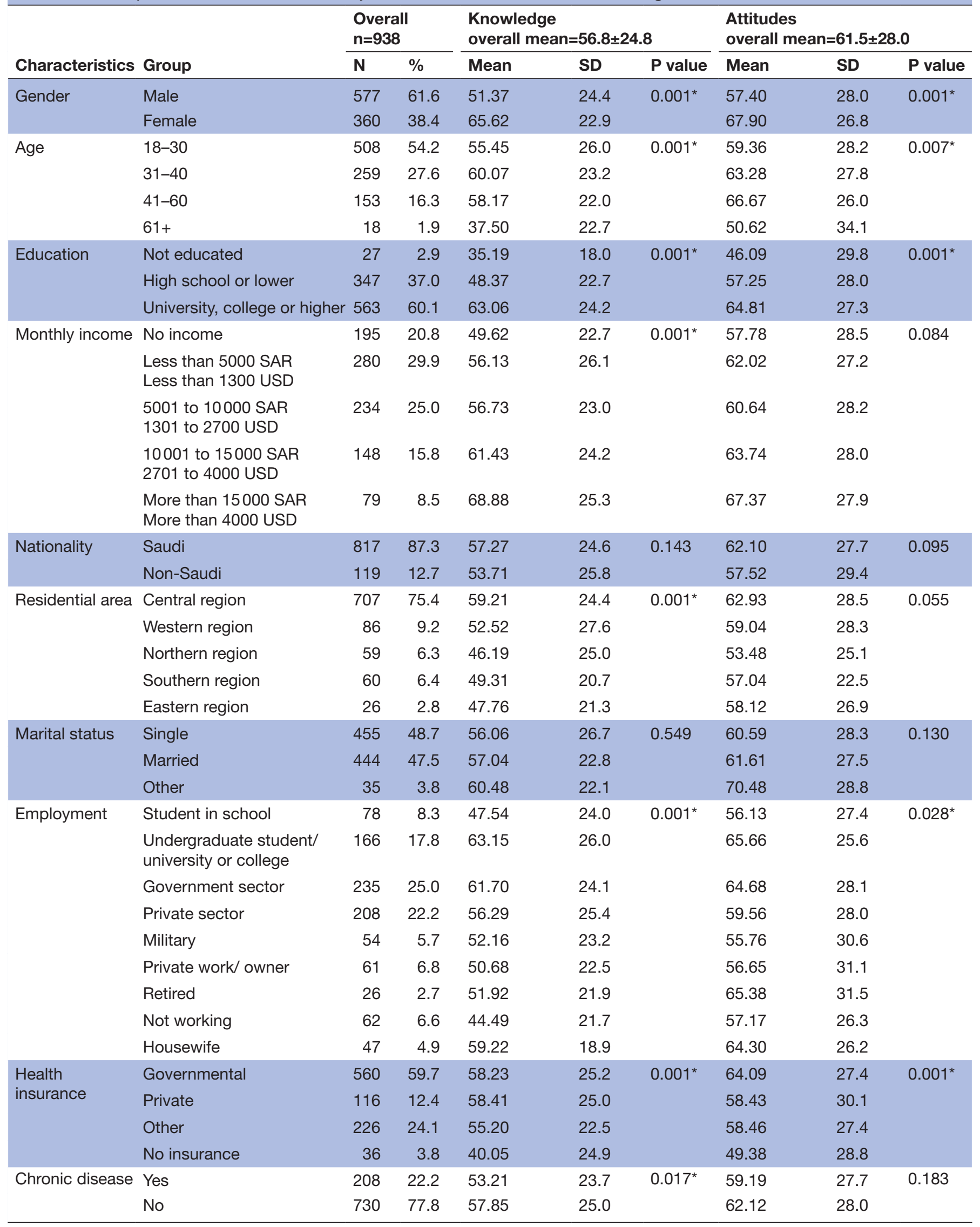


Table 1 Continued

\begin{tabular}{|c|c|c|c|c|c|c|c|c|c|}
\hline \multirow[b]{2}{*}{ Characteristics } & \multirow[b]{2}{*}{ Group } & \multicolumn{2}{|c|}{$\begin{array}{l}\text { Overall } \\
\mathrm{n}=938\end{array}$} & \multicolumn{3}{|c|}{$\begin{array}{l}\text { Knowledge } \\
\text { overall mean }=56.8 \pm 24.8\end{array}$} & \multicolumn{3}{|c|}{$\begin{array}{l}\text { Attitudes } \\
\text { overall mean }=61.5 \pm 28.0\end{array}$} \\
\hline & & $\mathbf{N}$ & $\%$ & Mean & SD & $P$ value & Mean & SD & $P$ value \\
\hline $\begin{array}{l}\text { Medical } \\
\text { background }\end{array}$ & No & 677 & 72.3 & 53.37 & 23.1 & & 59.23 & 27.9 & \\
\hline \multirow{3}{*}{$\begin{array}{l}\text { Previous } \\
\text { medical } \\
\text { research } \\
\text { participation }\end{array}$} & Yes & 149 & 15.9 & 65.83 & 25.8 & $0.001^{*}$ & 66.44 & 27.6 & $0.001^{*}$ \\
\hline & No & 737 & 78.6 & 55.54 & 24.3 & & 60.65 & 28.1 & \\
\hline & Not sure & 41 & 4.4 & 48.98 & 22.3 & & 57.45 & 26.0 & \\
\hline \multirow{2}{*}{$\begin{array}{l}\text { Do you know } \\
\text { somebody who } \\
\text { has participated } \\
\text { in medical } \\
\text { research? }\end{array}$} & Yes & 248 & 26.5 & 60.42 & 24.6 & $0.001^{*}$ & 62.23 & 27.6 & 0.100 \\
\hline & No & 596 & 63.6 & 57.30 & 24.6 & & 62.99 & 27.8 & \\
\hline
\end{tabular}

*Significant at $\alpha=0.05$.

SAR, Saudi Arabian riyal; USD, United States dollar.

determine the factors independently associated with knowledge of and attitudes toward CTs. In this model, we controlled for gender, age, education, monthly income, nationality, residential area, marital status, employment, health insurance, chronic disease, medical background, previous medical research participation and medical research participation by someone close. All calculations were performed using SPSS V.23 (SPSS Inc, Chicago, Illinois, USA).

\section{RESULTS}

\section{Participant characteristics}

A total of 1084 members of the public were approached to participate in the study. In total, 938 (86.5\%) agreed to complete the questionnaire. Of the 938 participants, most were males $(61.6 \%)$. The age groups with the highest representation were 18 to 30 years $(54.2 \%)$ and 31 to 40 years $(27.6 \%)$. The majority of the participants $(60.1 \%)$ reported achieving a tertiary educational level and $75.7 \%$ reported a monthly income of equal or less than 10000 Saudi Arabian riyal, which is equivalent to approximately 2700 United States dollars. Approximately half of the participants were single $(48.7 \%)$, and $22.2 \%$ indicated having been diagnosed with a chronic disease. Just more than a quarter $(27.7 \%)$ of the sample had a medical background (working in a healthcare facility or having health-related education). A small group (15.9\%) declared that they had previously participated in medical research, and $26.5 \%$ knew someone who had participated in medical research in the past (table 1).

\section{Knowledge about clinical trials in the KSA}

The overall percentage mean score \pm SD for knowledge regarding CTs was 56.8 \pm 24.8 . Although some participants were not aware of the term, almost half $(43.7 \%)$ could define the concept correctly. Most of the participants $(71.8 \%)$ agreed that CTs are subject to ethical guidelines, but only $26.8 \%$ were aware of the concept of an institutional review board (table 2). The majority (81.1\%) was aware of the Saudi Food and Drug Authority (SFDA), and $66.4 \%$ were aware of the SFDA role in the regulation of CTs. Most of the participants $(72.1 \%)$ agreed that CTs benefit the community, and $46.5 \%$ responded correctly regarding the benefits of CTs for the study participants. Approximately half of the sample was aware of the conditions governing the initiation of CTs $(56.0 \%)$ as well as the right of CT participants to withdraw from a study at any time $(47.6 \%)$. Other findings from the knowledge section of the questionnaire are listed in table 2.

\section{Attitudes toward CTs in the KSA}

The overall percentage mean score $\pm \mathrm{SD}$ for Saudi attitudes toward CTs was $61.5 \pm 28.0$ out of 100 . Most of the participants $(59.5 \%)$ had a positive attitude toward testing new drugs on adult patients in the KSA, and $63.2 \%$ were positive about testing approved/off-label drugs (approved and marketed drugs for other indications) on patients. However, only $30.5 \%$ of the participants were positive about conducting CTs using healthy volunteers (Phase I). The attitudes were similar for paediatric CTs, as $48.2 \%$ and $56.4 \%$ agreed with testing new drugs or approved/ off-label drugs on paediatric patients, respectively. The majority of the participants $(72.7 \%)$ agreed that CTs are important in terms of drug development, and $69.1 \%$ showed at least possibility of participating in a CT should they or a close family member be presented with the opportunity. The majority of the participants $(86.8 \%)$ indicated a willingness to learn more about CTs. Other findings from the attitude section of the questionnaire are listed in table 3. 


\begin{tabular}{|c|c|}
\hline Variables & $\begin{array}{l}n \text { ( } \% \text { of } \\
\text { participants) }\end{array}$ \\
\hline \multicolumn{2}{|l|}{ Have you heard about clinical trials? } \\
\hline Yes & $289(30.8)$ \\
\hline No/not sure & $648(69.1)$ \\
\hline \multicolumn{2}{|l|}{ What is the definition of a clinical trial? } \\
\hline $\begin{array}{l}\text { Studies in clinics to survey patients' } \\
\text { opinions about healthcare topics }\end{array}$ & $139(14.8)$ \\
\hline Experiments on animals & $119(12.7)$ \\
\hline $\begin{array}{l}\text { Studies to test new drugs or procedures } \\
\text { on humans }\end{array}$ & $410(43.7)$ \\
\hline Graduation projects for medical students & $62(6.6)$ \\
\hline Not sure & $208(22.2)$ \\
\hline \multicolumn{2}{|l|}{ Have you heard about an IRB? } \\
\hline Yes & $251(26.8)$ \\
\hline No & $685(73.1)$ \\
\hline \multicolumn{2}{|l|}{ Have you heard of the SFDA? } \\
\hline Yes & $761(81.1)$ \\
\hline No & $177(18.9)$ \\
\hline
\end{tabular}

Does the SFDA play a role in regulating clinical trials?
Yes
$622(66.4)$
No
$315(33.6)$

Are there ethical guidelines to regulate the conduct of clinical trials?

$\begin{array}{ll}\text { Yes } & 673(71.8) \\ \text { No } & 265(28.3)\end{array}$

Are there direct benefits for participants in clinical trials?

\begin{tabular}{lc} 
Definitely & $313(33.4)$ \\
Definitely not & $35(3.7)$ \\
No benefit or harm & $19(2.0)$ \\
Possible benefit or harm & $436(46.5)$ \\
Not sure & $135(14.4)$ \\
Do clinical trials have direct benefits for the community? \\
Yes & $676(72.1)$ \\
No & $262(27.9)$ \\
When can an investigator start clinical trials? & $42(4.5)$ \\
Any time they want & $135(14.4)$ \\
Only with participant agreement & $41(4.4)$ \\
After obtaining manager approval & $525(56.0)$ \\
\hline They should obtain approval from & $195(20.8)$ \\
responsible authorities & $250(26.7)$ \\
Not sure & $687(73.3)$ \\
Can an investigator recruit patients without their approval? & \\
Yes &
\end{tabular}

Can participants freely withdraw from clinical trials anytime?
Yes
446 (47.6)

Continued
Table 2 Continued

\begin{tabular}{ll} 
Variables & $\begin{array}{l}\boldsymbol{n} \text { (\% of } \\
\text { participants) }\end{array}$ \\
\hline No & $492(52.5)$ \\
$\begin{array}{l}\text { May published articles include confidential patient } \\
\text { information (eg, names)? }\end{array}$ \\
Yes & $318(33.9)$ \\
No & $620(66.1)$ \\
Knowledge score out of 100 (12 questions) & $\mathbf{5 6 . 8 \pm 2 4 . 8}$
\end{tabular}

IRB, Institutional Review Board; SFDA, Saudi Food and Drug Authority.

\section{Factors associated with increased knowledge and more positive attitudes toward CTs}

The univariate analysis revealed that females had a higher level of knowledge about CTs than males. In addition, participants in the 31 o 40 age group had the highest level of knowledge (table 1). CT-related knowledge increased with an increased level of education $(p=0.001)$ as well as an increased monthly income $(\mathrm{p}=0.001)$. Participants from the Central region of the KSA had a higher level knowledge compared with those from other regions $(p=0.001)$ (table 1). Undergraduate students and governmental employees had a higher level of knowledge compared with those from other employment categories $(p=0.001)$ (table 1$)$. Having governmental or private health insurance $(\mathrm{p}=0.001)$ was associated with a higher level of CT-related knowledge. Noteworthy is that participants without chronic diseases had a higher level of knowledge than those with chronic diseases $(\mathrm{p}=0.017)$. Previous participation in medical research or knowing someone who had participated was associated with better CT-related knowledge $(\mathrm{p}=0.001)$ (table 1).

After adjusting for possible confounders, the beta coefficients for participants who were male $(\mathrm{B}=-14.1 ; \mathrm{p}=0.001)$, uneducated $(\mathrm{B}=-19.6 ; \mathrm{p}=0.001)$ and low income $(\mathrm{B}=-9.7$; $\mathrm{p}=0.011$ for no income, $\mathrm{B}=-9.1 ; \mathrm{p}=0.005$ for $5000 \mathrm{SAR}$ or less and $\mathrm{B}=-6.9 ; \mathrm{p}=0.022$ for 6000 to $10000 \mathrm{SAR}$ ) and who had no medical background $(\mathrm{B}=-4.7 ; \mathrm{p}=0.015)$ had significantly lower knowledge scores. By contrast, participants aged 41 to 60 years $(\mathrm{B}=12.1 ; \mathrm{p}=0.036)$ and those with health insurance $(B=12.9 ; p=0.003$ for govermental, $\mathrm{B}=16.5 ; \mathrm{p}=0.001$ for private and $\mathrm{B}=12.8 ; \mathrm{p}=0.003$ for other) were more knowledgeable regarding CTs (table 4).

In terms of attitudes, females were more positive toward CTs $(p=0.001)$ than males. The 31 to 40 and 41 to 60 age groups were more positive compared with other age categories $(p=0.007)$, and having a higher educational level was also associated with a more positive attitude ( $\mathrm{p}=0.001)$ (table 1$)$. As with the knowledge section, undergraduate students and governmental employees were more positive toward CTs $(p=0.028)$ than participants in other employment categories (table 1), as were those with governmental or private health insurance $(p=0.001)$. Participants with a 
Table 3 Participants' attitude-related responses

\begin{tabular}{|c|c|}
\hline Variables & $n(\%)$ \\
\hline \multicolumn{2}{|c|}{ Do you agree with testing new drugs on patients? } \\
\hline Yes & $558(59.5)$ \\
\hline No/not sure & $380(40.5)$ \\
\hline \multicolumn{2}{|c|}{ Do you agree with testing approved drugs on patients? } \\
\hline Yes & $593(63.2)$ \\
\hline No/not sure & $345(36.8)$ \\
\hline \multicolumn{2}{|c|}{ Do you agree with testing new drugs on healthy volunteers? } \\
\hline Yes & $286(30.5)$ \\
\hline No/not sure & $651(69.5)$ \\
\hline \multicolumn{2}{|c|}{ Do you agree with testing new drugs on paediatric patients? } \\
\hline Yes & $452(48.2)$ \\
\hline No/not sure & $485(51.8)$ \\
\hline \multicolumn{2}{|c|}{$\begin{array}{l}\text { Do you agree with testing approved drugs on paediatric } \\
\text { patients? }\end{array}$} \\
\hline Yes & $528(56.4)$ \\
\hline No/not sure & $409(43.7)$ \\
\hline
\end{tabular}

Do you agree with participating/having a family member participate in clinical trials?

\begin{tabular}{|c|c|}
\hline Yes & $252(26.9)$ \\
\hline Possibly & $395(42.2)$ \\
\hline No/not sure & $290(31.0)$ \\
\hline \multicolumn{2}{|c|}{ What is your perception regarding clinical trials? } \\
\hline Not important & $41(4.4)$ \\
\hline $\begin{array}{l}\text { Very important for drug } \\
\text { development }\end{array}$ & $682(72.7)$ \\
\hline $\begin{array}{l}\text { Important only for pharmaceutical } \\
\text { companies to earn money }\end{array}$ & $54(5.8)$ \\
\hline Not sure & $161(17.2)$ \\
\hline \multicolumn{2}{|c|}{ Are you willing to learn about clinical trials? } \\
\hline Yes & $814(86.8)$ \\
\hline No & $124(13.2)$ \\
\hline \multicolumn{2}{|l|}{ Do you trust research teams? } \\
\hline Yes & $629(67.1)$ \\
\hline No/not sure & 309 (32.9) \\
\hline $\begin{array}{l}\text { Attitude score out of } 100 \text { (9 } \\
\text { questions) }\end{array}$ & $61.5 \pm 28.0$ \\
\hline
\end{tabular}

medical background or who had previously participated in medical research tended to be more positive ( $\mathrm{p}=0.001)$ compared with participants with no medical background or who had never participated in medical research (table 1).

After adjusting for the possible confounders, participants who were male $(B=-9.2 ; p=0.001)$, uneducated $(\mathrm{B}=-18.4, \mathrm{p}=0.004)$ or did not have a medical background $(\mathrm{B}=-5.0 ; \mathrm{p}=0.039)$ were associated with more negative attitudes toward CTs (table 4).
Correlation between Saudi public's knowledge of and attitudes toward clinical trials

Our results indicated a moderately positive relationship between the Saudi public's knowledge of and attitudes toward CTs (Pearson's $r=0.564, \mathrm{p}=0.0001$ ). Therefore, we predict that as the Saudi public's knowledge of CTs increases, they will become more positive toward CTs.

\section{DISCUSSION}

This public survey revealed a general lack of knowledge regarding CTs. Most of the participants could not identify or correctly define the term 'CT'. Although most of the participants were aware of the voluntary nature of participation in CTs, they were not aware of their right to withdraw from CTs. The current results are supported by similar findings in studies conducted in healthcare settings (with patients and/or their families) within the KSA. ${ }^{17-20}$ The reason may be the lack of institutional and national campaigns promoting CTs. ${ }^{525}$

Although most of the participants agreed that CTs are governed by ethical principles, they were not aware of Institutional Review Boards (IRBs) and their role in protecting human participants. In a study conducted in a healthcare setting, Sheblaq et al reported that the majority of the patients diagnosed with cancer were not aware of the role of the IRB. ${ }^{17}$ The public tends to expect the authorities to protect them, even though they are not aware of exactly who plays this role. We observed this phenomenon repeatedly when participants responded positively to questions regarding their trust in the study team and in their compliance with regulatory guidelines when initiating a trial or recruiting participants. The Saudi public recognised the SFDA and its role in CTs, most likely owing to their well-known food and drug-related regulatory activities in the KSA.

The Saudi public's overall attitude toward participation in CTs was moderately positive. The Saudi public agrees that CTs may be beneficial for both society as a whole and individual participants. In addition, trust in the study team may explain the favourable attitude toward participation in CTs. It could be argued that participant responses may change in real-life situations such as in healthcare settings. However, our results are consistent with other studies investigating the opinions of patients and families regarding participation in CTs in the KSA. ${ }^{16-18}$

Similarly, but to a lesser degree, the Saudi public agreed with the idea of conducting paediatric CTs for approved/ off-label drugs. However, only $48 \%$ of the participants indicated that it is acceptable to test new drugs on paediatric participants. Objection to the use of new drugs or vaccines was one of the factors underlying the opposition to paediatric CTs. ${ }^{26}$ Although the study did not explore the reasons underpinning the objections to participating in CTs, we believe that the fear of adverse events, as well as safety concerns, may have been responsible..$^{25} 27$

Phase I CTs, which often involve testing new drugs on healthy volunteers, are important in the process of drug 


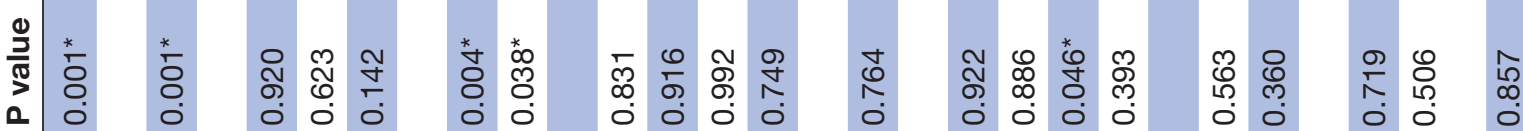

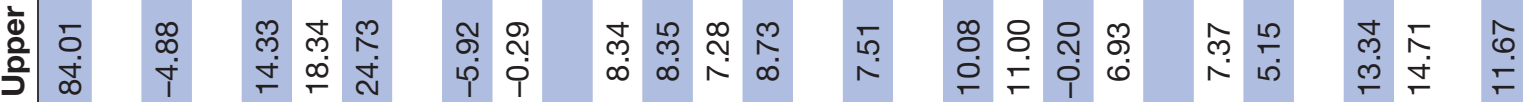

$\frac{\overline{0}}{\frac{\pi}{\pi}}$

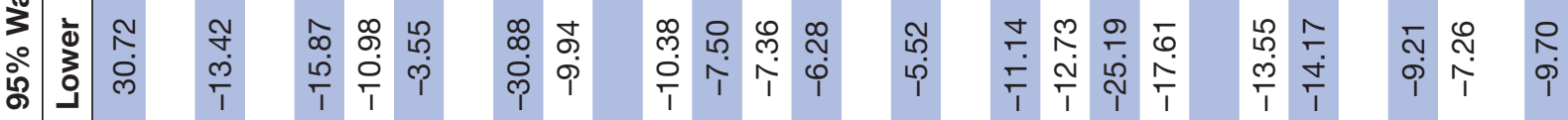

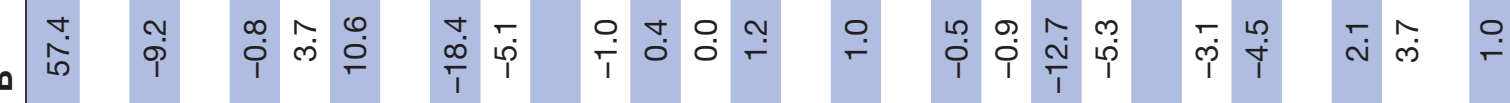
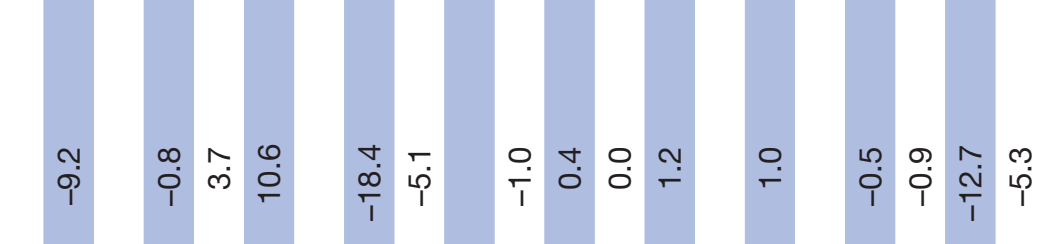

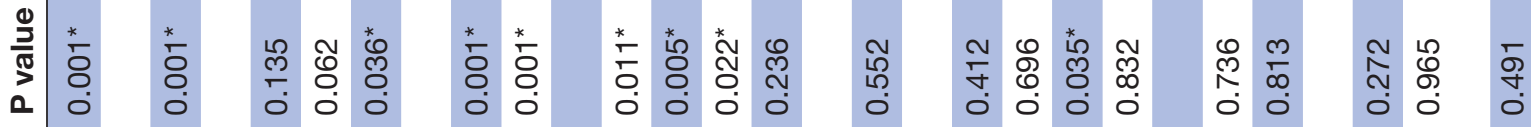

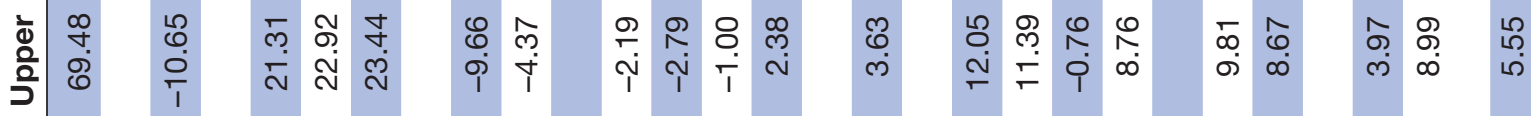

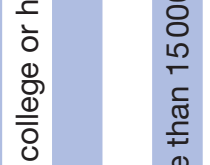

n r c n N $\frac{\overparen{D}}{\stackrel{0}{\sigma}}$ 


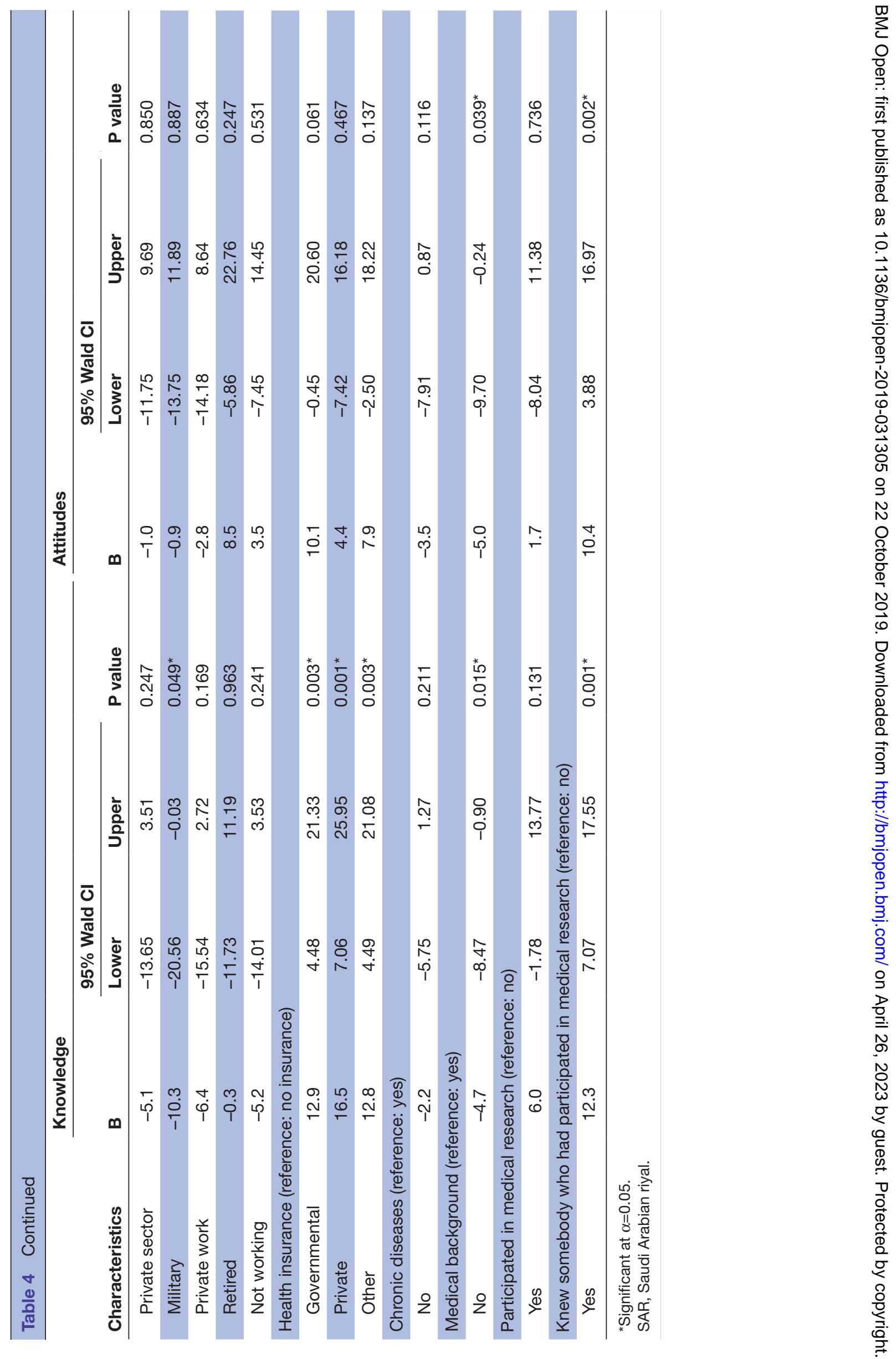


development. However, several ethical dilemmas influence conducting such studies with healthy volunteers and patients. ${ }^{28}$ In our study, the Saudi public displayed negative attitudes toward testing new drugs on healthy volunteers. Only $30.5 \%$ of the participants agreed with the idea of conducting CTs on healthy volunteers in the KSA. This sentiment may be related to the lack of knowledge regarding the purpose of testing new drugs on healthy volunteers. Conducting public educational campaigns about CTs is necessary for improving the Saudi public's knowledge and awareness about CTs.

Consistent with other studies, ${ }^{911}$ participants' attitudes toward CTs were markedly dependent on their knowledge of CTs. We predict that as their knowledge increases, the Saudi public will become more positive regarding CTs. A low level of knowledge regarding CTs may indicate misunderstanding or confusion regarding the purposes of the different phases of CTs. In turn, participants' answers may have been affected by insufficient knowledge. We believe that many participants used their common sense to answer some survey questions and may have begun to recognise the meaning of CTs while answering further questions. These observations support the need for CT-related public educational campaigns, since the majority of the participants were interested in learning more about CTs.

Male gender, lower education, lack of a medical background, lower monthly income, a lower age group and lack of health insurance were independently associated with a low level of knowledge regarding CTs among the Saudi public. Male gender, less education and the lack of a medical background were independently associated with negative attitudes toward CTs. Our results are consistent with an American household survey conducted to assess the level of public participation in and awareness of clinical and translational research, where higher levels of income and education were associated with higher participation and awareness. ${ }^{29}$ In a study conducted with patients diagnosed with cancer in a healthcare setting, lower educational and income levels, as well as race and ethnicity, were associated with decreased awareness of CTs. ${ }^{9}$ Similarly, lower income and education were associated with a reduced willingness to participate in CTs in African-American patients diagnosed with cancer. ${ }^{30}$ A study of patients with cancer in the KSA found that higher education was the only significant predictor of trial participation. ${ }^{17}$

Unlike other studies with the public or in healthcare settings, ${ }^{5} 92531-33$ gender was independently associated with knowledge and attitudes. Males were associated with a lower level of knowledge and with a more negative attitude toward CTs. The underlying rationale has not been clearly discussed in the literature. Gender differences regarding knowledge of and attitudes toward CTs should be considered in future studies.

In the previous studies investigating knowledge of and attitudes toward CTs in the KSA, sample sizes were much smaller than ours and mainly involved patients and/or their families in healthcare settings. ${ }^{17} 18$ To our knowledge, this is the first Saudi study exploring the public's knowledge of and attitudes toward CTs outside of a healthcare setting. Furthermore, it is the first study to solicit public perspectives regarding the different phases of CTs conducted in adult and paediatric populations.

\section{CONCLUSION}

The Saudi public has a low level of knowledge and moderately positive attitudes toward CTs. Increasing the Saudi public's knowledge may contribute to positive attitudes toward participation in and support of CTs; this supports our proposition of educational campaigns to increase awareness and knowledge of CTs. These campaigns should target the less knowledgeable subgroups identified in this study and focus on the importance of evaluating new drugs on healthy volunteers (Phase I clinical trials). In addition, our results support conducting and investing in CTs in the KSA. Conducting similar studies in the future, taking the limitations of this study into consideration, may facilitate measuring the improvement of knowledge over time. We also recommend in-depth qualitative and focus group-based studies for a deeper understanding of participant perspectives.

\section{Study limitations}

The main limitation in this study is related to possible selection bias due to the use of convenience sampling; however the effect of this limitation may have been minimised by the large sample size and the diversity of the visitors. For example, in our sample, the distribution of males $(61.6 \%)$ was slightly higher than in the general population, while in the 31 to 40 age group, it was $27.6 \%$, which is slightly lower than in the general population.

Contributors AMD and NAR: Conception and design, data acquisition, data collection, analytical plan and drafting of the manuscript. RD: Conception and design and data acquisition. MAJ: Conception and design, data acquisition and supervision. EAQ: Conception and design and data collection. All authors have critically revised the manuscript for important intellectual content, approve of the final version to be published and agree to be accountable for all aspects of the work.

Funding This study was supported by research grant RC16/010/R from the King Abdullah International Medical Research Center, Riyadh, Saudi Arabai.

\section{Competing interests None declared.}

Patient consent for publication Not required.

Ethics approval This study was approved by the Institutional Review Board at King Abdulaziz Medical City, Riyadh, KSA.

Provenance and peer review Not commissioned; externally peer reviewed.

Data availability statement Data are available upon reasonable request.

Open access This is an open access article distributed in accordance with the Creative Commons Attribution Non Commercial (CC BY-NC 4.0) license, which permits others to distribute, remix, adapt, build upon this work non-commercially, and license their derivative works on different terms, provided the original work is properly cited, appropriate credit is given, any changes made indicated, and the use is non-commercial. See: http://creativecommons.org/licenses/by-nc/4.0/.

ORCID iD

Ahmad M Deeb http://orcid.org/0000-0002-3680-7338 


\section{REFERENCES}

1 Centre for Evidence-Based Medicine. Oxford centre for evidencebased medicine - levels of evidence, 2009. Available: https://www. cebm.net/2009/06/oxford-centre-evidence-based-medicine-levelsevidence-march-2009/

2 Wyse RK. Accelerating patient recruitment in clinical trials: in-depth report from the SMi 2 nd annual conference. In: Ross C, ed. The SMi 2nd annual conference. London: NetworkPharma Ltd, 2006: 7-19.

3 Verheggen F, Nieman F, Reerink E, et al. Patient satisfaction with clinical trial participation. Int J Qual Health Care 1998;10:319-30.

4 Institute of Medicine (US). Public engagement and clinical trials: new models and disruptive technologies: workshop summary. Washington: National Academies Press, 2012.

5 Leiter A, Diefenbach MA, Doucette J, et al. Clinical trial awareness: changes over time and sociodemographic disparities. Clin Trials 2015;12:215-23.

6 The Need for Awareness of Clinical Research. National Institute of health, 2016. Available: https://www.nih.gov/health-information/ nih-clinical-research-trials-you/need-awareness-clinical-research [Accessed 10 Sep 2019].

7 Kim S-H, Tanner A, Friedman DB, et al. Barriers to clinical trial participation: comparing perceptions and knowledge of African American and white South Carolinians. J Health Commun 2015;20:816-26.

$8 \mathrm{Kim}$ S-H, Tanner A, Friedman DB, et al. Barriers to clinical trial participation: a comparison of rural and urban communities in South Carolina. J Community Health 2014;39:562-71.

9 Lara PN, Paterniti DA, Chiechi C, et al. Evaluation of factors affecting awareness of and willingness to participate in cancer clinical trials. $J$ Clin Oncol 2005;23:9282-9.

10 Joshi V, Kulkarni A. Public awareness of clinical trials: a qualitative pilot study in Pune. Perspect Clin Res 2012;3:125-32.

11 Miller SM, Hudson SV, Egleston BL, et al. The relationships among knowledge, self-efficacy, preparedness, decisional conflict, and decisions to participate in a cancer clinical trial. Psychooncology 2013;22:481-9.

12 Denicoff AM, McCaskill-Stevens W, Grubbs SS, et al. The National cancer Institute-American Society of clinical oncology cancer trial Accrual symposium: summary and recommendations. J Oncol Pract 2013;9:267-76.

13 Trantham LC, Carpenter WR, DiMartino LD, et al. Perceptions of cancer clinical research among African American men in North Carolina. J Natl Med Assoc 2015;107:33-41.

14 Featherstone K, Donovan JL. "Why don't they just tell me straight, why allocate it?" The struggle to make sense of participating in a randomised controlled trial. Soc Sci Med 2002;55:709-19.

15 Jamjoom A, Jamjoom A, Samman A, et al. Fate of registered clinical trials performed in Saudi Arabia. Saudi Med J 2015;36:1245-8.

16 Bazarbashi S, Hassan A, Eldin AM, et al. Awareness and perceptions of clinical trials in cancer patients and their families in Saudi Arabia. J Cancer Educ 2015;30:655-9.
17 Sheblaq NR, Traifi S, Sakiani MA, et al. Awareness and attitude of cancer patients about participation in clinical research (CR) in Saudi Arabia. J Clin Oncol 2013:e17528.

18 Al-Tannir MA, El-Bakri N, Abu-Shaheen AK. Knowledge, attitudes and perceptions of Saudis towards participating in clinical trials. PLoS One 2016;11:e0143893.

19 Al-Dakhil LO, Alanazy R, Al-Hamed RE, et al. Attitudes of patients in developing countries toward participating in clinical trials: a survey of Saudi patients attending primary health care services. Oman Med J 2016;31:284-9.

20 Almutairi KM, Alonazi WB, Alodhayani AA, et al. Barriers to cancer clinical trial participation among Saudi nationals: a cross-sectional study. J Relig Health 2017;56:623-34.

21 The Central Department of Statistics and Information. Demography survey 2016, 2017. Available: https://www.stats.gov.sa/sites/default/ files/en-demographic-research-2016_4.pdf [Accessed 24 Apr 2017].

22 Abdullahi A, Hassan A, Kadarman N, et al. Food safety knowledge, attitude, and practice toward compliance with abattoir laws among the abattoir workers in Malaysia. Int J Gen Med 2016;9:79-87.

23 Nur Ain M, Azfar M, Omarulharis S, et al. Knowledge, attitude and practice of dengue prevention among sub urban community in Sepang, Selangor. International Journal of Public Health and Clinical Sciences 2017;4:73-83.

24 Malhotra V, Kaura S, Sharma H. Knowledge, attitude and practices about hepatitis $B$ and infection control measures among dental students in Patiala. J Dent Allied Sci 2017;6:65-9.

25 Choi YJ, Beck S-H, Kang WY, et al. Knowledge and perception about clinical research shapes behavior: face to face survey in Korean General public. J Korean Med Sci 2016;31:674-81.

26 Nasef N, Shabaan A, Mohammed S, et al. Factors influencing parental consent for participation in clinical research involving their children in Egypt. East Mediterr Health J 2014;20:162-8.

27 Nabulsi M, Khalil Y, Makhoul J. Parental attitudes towards and perceptions of their children's participation in clinical research: a developing-country perspective. J Med Ethics 2011;37:420-3.

28 Elliott C, Abadie R. Exploiting a research underclass in phase 1 clinical trials. N Engl J Med 2008;358:2316-7.

29 Davis MM, Clark SJ, Butchart AT, et al. Public participation in, and awareness about, medical research opportunities in the era of clinical and translational research. Clin Trans/ Sci 2013;6:88-93.

30 Advani AS, Atkeson B, Brown CL, et al. Barriers to the participation of African-American patients with cancer in clinical trials. Cancer 2003;97:1499-506.

31 Comis RL, Miller JD, Aldigé CR, et al. Public attitudes toward participation in cancer clinical trials. J Clin Oncol 2003;21:830-5.

32 Joshi V, Kulkarni A, Oka G, et al. Public awareness and perception of clinical trials: quantitative study in Pune. Perspect Clin Res 2013;4:169-74.

33 Ohmann C, Deimling A. Attitude towards clinical trials: results of a survey of persons interested in research. Inflamm Res 2004;53:S142-7. 